\title{
Molecular Diversity Analysis in Turmeric (Curcuma longa L.) Using SSR Markers
}

\author{
Thokchom Joydeep Singh", R.K. Patel, Savankumar N. Patel and Priya A. Patel \\ Department of Genetics and Plant Breeding, Navsari Agricultural University, \\ Navsari (Gujarat) - 396450, India \\ *Corresponding author
}

\section{A B S T R A C T}

\section{Keywords \\ Genetic diversity, \\ Polymorphism, SSR \\ markers, Dendogram, \\ Genotypes \\ Article Info \\ Accepted: \\ 07 October 2018 \\ Available Online: \\ 10 November 2018}

Total 9 SSR markers were utilized to study the genetic relatedness among all thirty genotypes of turmeric. Six identified SSR markers are highly informative for genetic studies and are extremely useful in distinguishing the polymorphism rate at a specific locus in turmeric. Primer pair's viz., 11 and 12, 5 and 6 and 13 and 14 generated higher levels of polymorphism and these could be used to differentiate turmeric genotypes under study. The molecular diversity analysis indicated presence of ample genetic diversity among the genotypes studied, which were grouped into 2 clusters. Similarity ratio revealed high degree of similarity to the extent of $100 \%$ between genotypes NVST-80 and Pratibha, NVST-55 and GNT-2 as well as NVST-53 indicating identical finger prints due to common origin. Very low level of similarity was observed between NVST-85 and NVST70 indicating higher amount of diversity among the genotypes.

\section{Introduction}

Turmeric (Curcuma longa L.) is one of the important perennial spice crop popularly known as "Indian saffron" belongs to family Zingiberaceae. It has chromosome number of $2 n=3 x=63$. It is originated in South East Asia and among which, India has achieved a predominant position as a largest producer of turmeric in the world. Besides India, it is cultivated in China, Taiwan, Indonesia, Sri Lanka, Thailand and other tropical countries but the highest diversity is concentrated in India and Thailand (Hikmat et al., 2011). Over eighty species are reported in the genus Curcuma from the Indo-Malayan region, from which fourty are the indigenous ones. India is the largest producer, consumer and exporter of turmeric in the world, which accounts for more than 50 per cent of the world trade (Chaudhary et al., 2006). The area under turmeric cultivation in India is $1,85,000$ hectares with an annual production of 9,57,000 metric tons and productivity is 5.17 metric tons per hectare (Anonymous, 2016).

In North East India (NEI) especially Mizoram, Meghalaya and Assam are endowed with a wide range of genetic variability in Curcuma longa and other related Curcuma species due to geo-climatic conditions of the region favouring higher accumulation of curcumin in rhizomes. The curcumin content is one of the major criteria for its export to the global 
markets. Alleppey turmeric is the world's most outstanding and demanded grade, which is the richest source of curcumin. Due to vegetative propagation and flowering complexities, the genetic improvement programmes in turmeric are largely restricted to clonal selection and induced mutation breeding. Moreover, limited viable seed settings in open-pollination and controlled crosses explore the possibility of recombination breeding through hybridization and hence few varieties such as IISR-Prabha and IISR-Pratibha have been released through progeny selection of open-pollinated seedlings. Even though, germplasm collection represents the main source of variability for turmeric genetic improvement. A comprehensive global taxonomic revision of the genus has not yet been attempted. Conventional taxonomic techniques in conjunction with molecular biology tools may go a long way in resolving the taxonomic confusion prevailing in the genus. DNA marker technology has provided an efficient tool to facilitate plant genetic resource conservation and its efficient management. In the current study, the use of Simple Sequence Repeats (SSR) markers is carried out considering the fact that they are highly reproducible due to their primer length and the high stringency achieved by the annealing temperature and provides highly polymorphic fingerprints. Hence, the experiment is design to assess the genetic diversity and characterization of the turmeric genotypes using molecular markers. Molecular marker techniques may also overcome many limitations of the morphological and biochemical markers for the discrimination of the turmeric accessions by providing genetic background for the observed phenotypic variability since they are not affected by the environment or developmental stage and can detect the variation at the DNA level. DNA markers can be used to measure the genetic drift in the available germplasm and to study the genetic diversity among the genotypes (Jan et al., 2011).

\section{Materials and Methods}

\section{Plant materials}

30 genotypes of turmeric (Curcuma longa L.) were used in the current study. Leaf samples were collected from the research farm of Dept. of Genetics and plant breeding, NAU, Navsari (Table 1).

\section{DNA extraction}

Total DNA was extracted from fresh leaves by the modified Cetyl Tri-methyl Ammonium Bromide (CTAB) method. The quality and concentration of extracted DNA were estimated by using Nanodrop machine. The DNA was spooled out, washed twice with $70 \%$ ethanol and dissolved in TE $(10 \mathrm{mM}$ Tris, $0.1 \mathrm{mM}$ EDTA, $\mathrm{pH}$ 8.0), incubated at $37^{\circ} \mathrm{C}$ for $30 \mathrm{~min}$ and extracted with chloroform: iso-amyl alcohol (24:1 v/v). DNA was re-precipitated and dissolved in TE buffer. DNA was checked for its quality and quantity by $0.8 \%$ agarose gel electrophoresis.

\section{PCR analysis and gel electrophoresis}

A set of 9 SSR markers were used (Table 2). The PCR reaction was carried out using Taq polymerase in $25 \mu \mathrm{l}$ reaction volume containing 10X PCR buffer, $2 \mathrm{mM} \mathrm{MgCl} 2,2.5$ $\mathrm{mg}$ of each dNTPs, 1 pmoles/ $\mu \mathrm{l}$ of forward and reverse primers each, $0.5 \mu \mathrm{l}$ (3 unit/ $\mu \mathrm{l})$ Taq polymerase and $50 \mathrm{ng}$ genomic DNA. The PCR reaction profile was used as follows: an initial hot start and denaturing step at $95^{\circ} \mathrm{C}$ for $7 \mathrm{~min}$ followed by 45 cycles at $94^{\circ} \mathrm{C}$ for 1 min, annealing at $55^{\circ} \mathrm{C}$ for $30 \mathrm{sec}$, primer elongation at $72^{\circ} \mathrm{C}$ for $2 \mathrm{~min}$ and final extension step at $72^{\circ} \mathrm{C}$ for $7 \mathrm{~min}$ were performed. The SSR-PCR products were analyzed on $2 \%$ agarose gel, visualized by 
staining with ethidium bromide and transillumination under short-wave UV light. DNA ladder used in the electrophoresis was of $100 \mathrm{bp}$ and 50bp.

\section{Data analysis}

Pair wise comparison of genotypes, based on the presence (1) or absence (0) of unique and shared polymorphic products was used to generate Jaccard's similarity coefficient by NT-SYS-pc version 2.02e software.

The similarity coefficient was used to construct a dendrogram by the unweighted pair group method with arithmetic averages (UPGMA). A combined analysis was performed by using dendrogram along with Jaccard's similarity coefficient matrix. The polymorphism information content (PIC) value described by Botstein et al., (1980) and modified by Anderson et al., (1993) for selfpollinated species was calculated as follows:

$$
\mathrm{PIC}_{\mathrm{i}}=\sum_{j=1}^{n} \mathrm{P}_{2 \mathrm{ij}}
$$

Where, pi equals the frequency of the $i^{\text {th }}$ allele and $p_{j}$ the frequency of the allele. Only the data from polymorphic loci were used for this analysis. The above mentioned methods were used for estimating the result. Markers which did not amplify any allele were shown as (-) symbol.

\section{Results and Discussion}

Based on dendrogram, the genotypes of turmeric under investigation grouped into two genetically diverse clusters. The UPGMA dendrogram (Figure 1) showed two main distinct clusters of turmeric genotypes, which were also genetically diverse amongst themselves. Cluster-I comprised of only one genotype (Sughandham) with coefficient of 1.00. Jaccard's similarity coefficient (Table 4) revealed that high degree of similarity to the extent of $100 \%$ between the varieties NVST80 and Pratibha, which revealed that these two genotypes were almost genetically similar. Same trend of results were also exhibited between genotypes NVST-71 and NVST-43; NVST-55 and GNT-2 as well as NVST-55 and NVST-53 with similarity coefficient of 1.00. All above genotypes were falling under same cluster.

The cluster-I consists of only one genotype of turmeric i.e. Sughandham. The similarity coefficient of this cluster range is 1 . Cluster-II was the largest and it included 29 genotypes of turmeric with similarity coefficients ranging between 0.44 to 1.0 . It is interesting to note that the Cluster-II is further divided into three sub clusters to simplify their comparative study. Sub cluster-I includes 4 turmeric genotypes viz., NVST-70, NVST-69, NVST66 and NVST-51. Sub cluster-II included 11 turmeric genotypes viz., NVST-68, NVST-97, NVST-42, NVST-98, NVST-41, NVST-48, NVST-52, NVST-71, NVST-43, NVST-80 and Pratibha. Similarly, sub cluster-III included 14 genotypes viz., NVST-56, NVST55, GNT-2, NVST-53, NVST-46, NVST-67, NVST-54, NVST-89, NVST-50, NVST-72, GNT-1, NVST-92, NVST-47 and NVST-85.

From the (Figure 1), it reveals that in cluster-II the genotype NVST-85 was distantly related to NVST-70 with similarity coefficient of 0.18 followed by NVST-55 with Pratibha and NVST-80 having similarity coefficients of 0.20 . High degree of similarity was found between variety NVST-80 and Pratibha, NVST-55 with GNT 2 as well as NVST-53 with similarity coefficient of 1.00 revealing genetic relatedness among genotypes. Based on study, the large range of similarity coefficient values for related genotypes using microsatellites provided greater confidence for assessment of genetic diversity and relationship. 
Table.2 List of 9 SSR primers and their sequences used in the genetic diversity analysis

\begin{tabular}{|c|c|c|c|c|}
\hline \multirow{2}{*}{$\begin{array}{l}\text { Sr. } \\
\text { No. }\end{array}$} & \multicolumn{4}{|c|}{ Primer sequences 5' - 3' } \\
\hline & FORWARD PRIMER & $\begin{array}{l}\text { Annealing } \\
\text { temperature }\end{array}$ & REVERSE PRIMER & $\begin{array}{l}\text { Annealing } \\
\text { temperature }\end{array}$ \\
\hline 1 & CATGCAAATGGAAATTGACAC (21) & 50.00 & TGATAAATTGACACATGGCAGTC (23) & 57.10 \\
\hline 2 & TCATTCAAAGTCCCATGGAA (20) & 53.20 & TTCGAGTGCAGAAGGAGAAATTA (23) & 57.10 \\
\hline 3 & TTCAACTTCTCCTCGCTCAG (20) & 57.30 & GCAAGGTCTGCATCTATTTCTC (23) & 58.40 \\
\hline 4 & AAACCGCAAGAAAACTGAAG (20) & 53.20 & CTCTTCCCTGAACGATTCC (19) & 56.70 \\
\hline 5 & ATGTGGTTGAGGAATGATGAGAC (26) & 61.60 & CTATTTCCCATAGCCCTTGTAGC (23) & 60.60 \\
\hline 6 & GTTCACAGCTTTAGCAGGGACAA (23) & 60.60 & СТССТСТССАТАТТСТССАТСТСG (24) & 62.70 \\
\hline 7 & TTGCCAGTGTGCTTGTTCTC (20) & 57.30 & TTGAAGGGAACACTGAAGGG (20) & 57.30 \\
\hline 8 & CCGGTGAGGGTGATATCTTG (20) & 59.40 & AAGCTCAAGCTCAAGCCAAT (20) & 55.30 \\
\hline 9 & GGAGGAGGCAGTTGATTTGT (20) & 57.30 & GCTTTGGTGGCTAGAGATGC (20) & 59.40 \\
\hline
\end{tabular}


Table.3 Polymorphism information content (PIC) of SSR loci across various genotypes of turmeric

\begin{tabular}{|c|c|c|c|c|c|c|c|}
\hline $\begin{array}{l}\text { Sr. } \\
\text { No. }\end{array}$ & $\begin{array}{l}\text { PRIMER } \\
\text { PAIR }\end{array}$ & SEQUENCES (5'-3') & $\begin{array}{c}\text { TOTAL } \\
\text { NUMBERS } \\
\text { OF } \\
\text { BANDS (a) }\end{array}$ & $\begin{array}{c}\text { TOTAL } \\
\text { NUMBER OF } \\
\text { POLYMORPHIC } \\
\text { BANDS (b) }\end{array}$ & $\begin{array}{l}\text { MONOMORPHIC } \\
\text { BANDS }\end{array}$ & $\begin{array}{l}\text { POLYMORPHISM } \\
\%(b / a X 100)\end{array}$ & $\begin{array}{c}\text { PIC } \\
\text { VALUE }\end{array}$ \\
\hline 1 & $1+2$ & $\begin{array}{l}\text { CATGCAAATGGAAATTGACAC }(\mathrm{F}) \\
\text { TGATAAATTGACACATGGCAGTC(R) }\end{array}$ & 2 & 2 & 0 & 100 & 0.51 \\
\hline 2 & $3+4$ & $\begin{array}{l}\text { TCATTAAAGTCCGATGGAA }(\mathrm{F}) \\
\text { TTCGATGCAGAAGGAG }(\mathrm{R})\end{array}$ & - & - & - & - & - \\
\hline 3 & $5+6$ & $\begin{array}{l}\text { TTCAACTTCTCCTCGCTC }(\mathrm{F}) \\
\text { GCAAGGTCTGCATCTATT }(\mathrm{R})\end{array}$ & 2 & 2 & 0 & 100 & 0.66 \\
\hline 4 & $7+8$ & $\begin{array}{l}\text { AAACCGCAAGAAAACTGA (F) } \\
\text { CTCTTGCCTGAACGATTCC (R) }\end{array}$ & - & - & - & - & - \\
\hline 5 & $9+10$ & $\begin{array}{l}\text { ATGTGGTTGAGGAATGAT }(\mathrm{F}) \\
\text { CTATTTCCCATAGCCCTT }(\mathrm{R})\end{array}$ & 2 & 2 & 0 & 100 & 0.60 \\
\hline 7 & $13+14$ & $\begin{array}{l}\text { TTGCCAGTGTGCTTGTTCTC (F) } \\
\text { TTGAAGGGAACACTGAAGGG (R) }\end{array}$ & 2 & 2 & 0 & 100 & 0.62 \\
\hline 8 & $15+16$ & $\begin{array}{l}\text { CCGGTGAGGGTGATATCTTG (F) } \\
\text { AAGCTCAAGCTCAAGCCAAT (R) }\end{array}$ & - & - & - & - & - \\
\hline 9 & $17+18$ & $\begin{array}{l}\text { GGAGGAGGCAGTTGATTTGT (F) } \\
\text { GCTTTGGTGGCTAGAGATGC (R) }\end{array}$ & 2 & 2 & 0 & 100 & 0.43 \\
\hline
\end{tabular}

$\mathrm{R}$ and $\mathrm{F}$ denotes reverse and forward primer, respectively. 
Table.4 Jaccard's similarity coefficient for thirty different genotypes of turmeric

\begin{tabular}{|c|c|c|c|c|c|c|c|c|c|c|c|c|c|c|c|c|c|c|c|c|c|c|c|c|c|c|c|c|c|c|}
\hline & 1 & 2 & 3 & 4 & 5 & 6 & 7 & 8 & 9 & 10 & 11 & 12 & 13 & 14 & 15 & 16 & 17 & 18 & 19 & 20 & 21 & 22 & 23 & 24 & 25 & 26 & 27 & 28 & 29 & 30 \\
\hline 1 & 1.00 & & & & & & & & & & & & & & & & & & & & & & & & & & & & & \\
\hline 2 & 0.67 & 1.00 & & & & & & & & & & & & & & & & & & & & & & & & & & & & \\
\hline 3 & 0.56 & 0.67 & 1.00 & & & & & & & & & & & & & & & & & & & & & & & & & & & \\
\hline 4 & 0.67 & 0.78 & 0.67 & 1.00 & & & & & & & & & & & & & & & & & & & & & & & & & & \\
\hline$\overline{5}$ & 0.27 & 0.50 & 0.56 & 0.36 & 1.00 & & & & & & & & & & & & & & & & & & & & & & & & & \\
\hline 6 & 0.60 & 0.70 & 0.78 & 0.70 & 0.60 & 1.00 & & & & & & & & & & & & & & & & & & & & & & & & \\
\hline 7 & 0.60 & 0.89 & 0.60 & 0.70 & 0.60 & 0.80 & 1.00 & & & & & & & & & & & & & & & & & & & & & & & \\
\hline$\overline{8}$ & 0.60 & 0.70 & 0.78 & 0.70 & 0.60 & 1.00 & 0.80 & 1.00 & & & & & & & & & & & & & & & & & & & & & & \\
\hline 9 & 0.60 & 0.55 & 0.45 & 0.70 & 0.33 & 0.64 & 0.64 & 0.64 & 1.00 & & & & & & & & & & & & & & & & & & & & & \\
\hline$\overline{10}$ & 0.30 & 0.40 & 0.63 & 0.40 & 0.63 & 0.67 & 0.50 & 0.67 & 0.50 & 1.00 & & & & & & & & & & & & & & & & & & & & \\
\hline 11 & 0.40 & 0.50 & 0.40 & 0.67 & 0.27 & 0.60 & 0.60 & 0.60 & 0.78 & 0.44 & 1.00 & & & & & & & & & & & & & & & & & & & \\
\hline$\overline{12}$ & 0.25 & 0.45 & 0.50 & 0.45 & 0.50 & 0.55 & 0.55 & 0.55 & 0.55 & 0.56 & 0.67 & 1.00 & & & & & & & & & & & & & & & & & & \\
\hline 13 & 0.30 & 0.40 & 0.63 & 0.40 & 0.44 & 0.67 & 0.50 & 0.67 & 0.50 & 0.71 & 0.63 & 0.75 & 1.00 & & & & & & & & & & & & & & & & & \\
\hline 14 & 0.36 & 0.60 & 0.50 & 0.45 & 0.50 & 0.70 & 0.70 & 0.70 & 0.55 & 0.56 & 1.00 & 0.78 & 0.75 & 1.00 & & & & & & & & & & & & & & & & \\
\hline 15 & 0.40 & 0.50 & 0.40 & 0.67 & 0.27 & 0.60 & 0.60 & 0.60 & 0.78 & 0.44 & 0.45 & 0.67 & 0.63 & 0.67 & 1.00 & & & & & & & & & & & & & & & \\
\hline 16 & 0.18 & 0.40 & 0.44 & 0.27 & 0.63 & 0.50 & 0.50 & 0.50 & 0.36 & 0.50 & 0.44 & 0.75 & 0.71 & 0.75 & 0.44 & 1.00 & & & & & & & & & & & & & & \\
\hline 17 & 0.50 & 0.63 & 0.50 & 0.63 & 0.20 & 0.56 & 0.56 & 0.56 & 0.56 & 0.38 & 0.71 & 0.44 & 0.57 & 0.63 & 0.71 & 0.38 & 1.00 & & & & & & & & & & & & & \\
\hline 18 & 0.50 & 0.63 & 0.50 & 0.63 & 0.20 & 0.56 & 0.56 & 0.56 & 0.56 & 0.38 & 0.71 & 0.44 & 0.57 & 0.63 & 0.71 & 0.38 & 0.42 & 1.00 & & & & & & & & & & & & \\
\hline 19 & 0.56 & 0.67 & 0.56 & 0.50 & 0.40 & 0.60 & 0.60 & 0.60 & 0.45 & 0.44 & 0.40 & 0.50 & 0.44 & 0.67 & 0.40 & 0.44 & 0.50 & 0.50 & 1.00 & & & & & & & & & & & \\
\hline 20 & 0.56 & 0.50 & 0.40 & 0.36 & 0.40 & 0.45 & 0.45 & 0.45 & 0.45 & 0.30 & 0.27 & 0.36 & 0.30 & 0.50 & 0.27 & 0.44 & 0.33 & 0.33 & 0.75 & 1.00 & & & & & & & & & & \\
\hline 21 & 0.75 & 0.67 & 0.40 & 0.50 & 0.27 & 0.45 & 0.60 & 0.45 & 0.60 & 0.30 & 0.40 & 0.36 & 0.30 & 0.50 & 0.40 & 0.30 & 0.50 & 0.50 & 0.75 & 0.75 & 1.00 & & & & & & & & & \\
\hline 22 & 0.56 & 0.50 & 0.75 & 0.50 & 0.56 & 0.78 & 0.60 & 0.78 & 0.45 & 0.63 & 0.40 & 0.50 & 0.63 & 0.50 & 0.40 & 0.44 & 0.33 & 0.33 & 0.56 & 0.40 & 0.40 & 1.00 & & & & & & & & \\
\hline 23 & 0.36 & 0.60 & 0.36 & 0.60 & 0.50 & 0.55 & 0.70 & 0.55 & 0.70 & 0.40 & 0.67 & 0.60 & 0.40 & 0.60 & 0.67 & 0.56 & 0.44 & 0.44 & 0.50 & 0.50 & 0.50 & 0.36 & 1.00 & & & & & & & \\
\hline 24 & 0.27 & 0.50 & 0.40 & 0.36 & 0.56 & 0.60 & 0.60 & 0.60 & 0.45 & 0.44 & 0.56 & 0.67 & 0.63 & 0.88 & 0.56 & 0.86 & 0.50 & 0.50 & 0.56 & 0.56 & 0.40 & 0.40 & 0.67 & 1.00 & & & & & & \\
\hline 25 & 0.60 & 0.70 & 0.78 & 0.70 & 0.60 & 1.00 & 0.80 & 1.00 & 0.64 & 0.67 & 0.60 & 0.55 & 0.67 & 0.70 & 0.60 & 0.50 & 0.56 & 0.56 & 0.60 & 0.45 & 0.45 & 0.78 & 0.55 & 0.60 & 1.00 & & & & & \\
\hline 26 & 0.27 & 0.50 & 0.56 & 0.36 & 0.75 & 0.60 & 0.60 & 0.60 & 0.33 & 0.44 & 0.27 & 0.50 & 0.44 & 0.50 & 0.27 & 0.63 & 0.20 & 0.20 & 0.40 & 0.40 & 0.27 & 0.56 & 0.50 & 0.56 & 0.60 & 1.00 & & & & \\
\hline 27 & 0.40 & 0.67 & 0.40 & 0.50 & 0.56 & 0.60 & 0.78 & 0.60 & 0.60 & 0.44 & 0.56 & 0.50 & 0.44 & 0.67 & 0.56 & 0.63 & 0.50 & 0.50 & 0.56 & 0.56 & 0.56 & 0.40 & 0.88 & 0.75 & 0.60 & 0.56 & 1.00 & & & \\
\hline 28 & 0.56 & 0.88 & 0.56 & 0.67 & 0.56 & 0.60 & 0.78 & 0.60 & 0.45 & 0.30 & 0.40 & 0.36 & 0.30 & 0.50 & 0.40 & 0.44 & 0.50 & 0.50 & 0.56 & 0.56 & 0.56 & 0.40 & 0.67 & 0.56 & 0.60 & 0.56 & 0.75 & 1.00 & & \\
\hline 29 & 0.40 & 0.36 & 0.56 & 0.36 & 0.75 & 0.60 & 0.45 & 0.60 & 0.45 & 0.63 & 0.27 & 0.36 & 0.44 & 0.36 & 0.27 & 0.44 & 0.20 & 0.20 & 0.27 & 0.40 & 0.27 & 0.56 & 0.36 & 0.40 & 0.60 & 0.56 & 0.40 & 0.40 & 1.00 & \\
\hline 30 & 0.44 & 0.40 & $\mathbf{0 . 3 0}$ & 0.40 & 0.44 & 0.50 & 0.50 & 0.50 & 0.67 & 0.50 & 0.44 & 0.27 & $\mathbf{0 . 3 3}$ & 0.40 & 0.44 & 0.33 & 0.38 & 0.38 & 0.30 & 0.44 & 0.44 & 0.30 & 0.56 & 0.44 & 0.50 & 0.30 & 0.63 & 0.44 & 0.63 & 1.00 \\
\hline
\end{tabular}

1-NVST 70, 2-NVST 68, 3-NVST 56, 4-NVST 98, 5-NVST 54, 6-NVST 55, 7-NVST 97, 8-GNT 2, 9-NVST 52, 10-NVST 67, 11-NVST 71, 12-NVST 72, 13GNT 1, 14-NVST 92, 15-NVST 43, 16-NVST 85, 17-NVST 80, 18-PRATIBHA, 19-NVST 66, 20-NVST 51, 21-NVST 69, 22-NVST 46, 23-NVST 41, 24NVST 47, 25-NVST 53, 26-NVST 89, 27-NVST 48, 28-NVST 42,,29-NVST 50, 30- SUGANDHAM. 
Fig.1 Dendrogram showing clustering of 30 genotypes of turmeric constructed by using UPGMA cluster analysis of genetic similarity based on SSR data

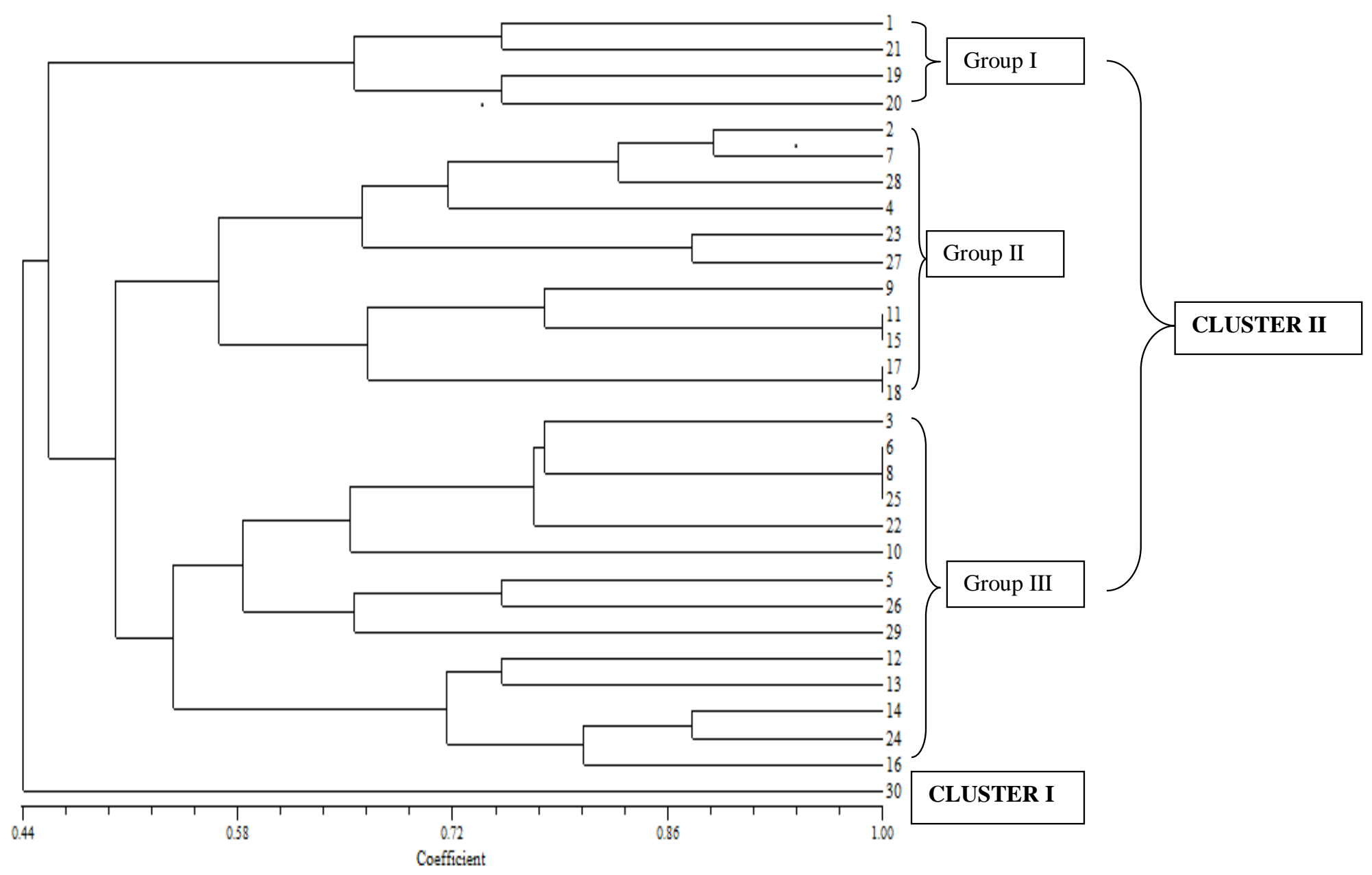

1-NVST 70, 2-NVST 68, 3-NVST 56, 4-NVST 98, 5-NVST 54, 6-NVST 55, 7-NVST 97, 8-GNT 2, 9-NVST 52, 10-NVST 67, 11-NVST 71, 12-NVST 72, 13-GNT 1, 14-NVST 92, 15-NVST 43, 16-NVST 85, 17-NVST 80, 18-PRATIBHA, 19-NVST 66, 20-NVST 51, 21-NVST 69, 22-NVST 46, 23-NVST 41, 24-NVST 47, 25-NVST 53, 26-NVST 89, 27-NVST 48, 28-NVST 42, ,29-NVST 50, 30- SUGANDHAM. 
Table.1 List of turmeric germplasm used in the experiment

\begin{tabular}{|c|c|c|c|c|c|}
\hline Sr. No & Genotype & Source & Sr. No & Genotype & Source \\
\hline 1) & NVST-41 & NAU, Navsari & 16) & NVST-68 & NAU, Navsari \\
\hline 2) & NVST-42 & NAU, Navsari & 17) & NVST-69 & NAU, Navsari \\
\hline 3) & NVST-43 & NAU, Navsari & 18) & NVST-70 & NAU, Navsari \\
\hline 4) & NVST-46 & NAU, Navsari & 19) & NVST-71 & NAU, Navsari \\
\hline 5) & NVST-47 & NAU, Navsari & 20) & NVST-72 & NAU, Navsari \\
\hline 6) & NVST-48 & NAU, Navsari & 21) & NVST-80 & NAU, Navsari \\
\hline 7) & NVST-50 & NAU, Navsari & 22) & NVST-85 & NAU, Navsari \\
\hline 8) & NVST-51 & NAU, Navsari & 23) & NVST-89 & NAU, Navsari \\
\hline 9) & NVST-52 & NAU, Navsari & 24) & NVST-92 & NAU, Navsari \\
\hline 10) & NVST-53 & NAU, Navsari & 25) & NVST-97 & NAU, Navsari \\
\hline 11) & NVST-54 & NAU, Navsari & 26) & NVST-98 & NAU, Navsari \\
\hline 12) & NVST-55 & NAU, Navsari & 27) & Pratibha & IISR, Calicut \\
\hline 13) & NVST-56 & NAU, Navsari & 28) & Sughandham & GAU, Jagudan \\
\hline 14) & NVST-66 & NAU, Navsari & 29) & GNT-1 & NAU, Navsari \\
\hline 15) & NVST-67 & NAU, Navsari & 30) & GNT-2 & NAU, Navsari \\
\hline
\end{tabular}

Out of 9, total six SSR markers resulted into polymorphism with banding pattern ranging from 1 to a maximum of 2 alleles per individual in all the loci. The results are in conformity with the studies conducted by Sasikumar (2005) (Table 3).

Six identified SSR markers are highly informative for genetic studies and are extremely useful in distinguishing the polymorphism rate at a specific locus in turmeric. McCouch et al., (2001) and Sasikumar (2005) reported a significantly greater allelic diversity of microsatellite markers than other molecular markers.

According to Akkaya and Buyukunal-Bal (2004), high PIC value can be attributed to the use of more informative markers. Highest PIC values were observed for SSR primer pairs 11 and 12 (0.67), 5 and 6 (0.66), 13 and 14 (0.62). PIC value is reflection of allele diversity and frequency among the genotypes. The markers showed an average PIC of 0.67 , which confirms that SSR markers used in this study were highly informative because markers with PIC values of 0.56 or higher are highly informative for genetic studies and are extremely useful in distinguishing the polymorphism rate of a marker at a specific locus.

This indicated that the genotypes used in the present study were more diverse due to differences in origin, ecotype and speciation. Microsatellite markers exhibit high PIC values because of their co dominant expression and multiallelism.

Similarity ratio revealed high degree of similarity to the extent of $100 \%$ between genotypes NVST-80 and Pratibha, NVST-55 and GNT-2 as well as NVST-53 indicating identical finger prints due to common origin. Identical microsatellite profiles in the studied microsatellite loci, suggested that the observed morphological differences between the cultivars may be associated with somatic mutations, which were not detectable with the used SSR markers. Hence, analysis of additional loci is necessary to identify and discriminate these accessions.

Very low level of similarity was observed between NVST-85 and NVST-70. Such kind of 
variation results from evolutionary phenomena like high mutation rate, replication slippage and unequal crossing over.

The main cause for a high level of polymorphism could be intra-specific variation as reported by Nayak et al., (2006), who demonstrated that high number of polymorphic loci revealed profound intra-specific variation among turmeric cultivars.

9 primers were screened, out of which 6 primers produced amplification. Primer pairs 1 and 2, 5 and 6, 9 and 10,11 and and 12,13 and 14, 17 and 18 proved to be finest as they showed $100 \%$ polymorphism with high PIC value. Based on banding pattern of SSR markers, dendogram was constructed using UPGMA method.

The similarity coefficient ranges from 0.44 to 1.00. The dendogram clearly divided the 30 genotypes into two main clusters. The result showed that there was an association between dendogram obtained by SSR analysis and morphological characters. Pairs of genotypes NVST-55 and GNT-2, NVST-55 and NVST-53, NVST-80 and Pratibha were genetically as well as morphologically related with each other.

\section{References}

Akkaya, M.S. and Bal, E. B. (2004). Assessment of genetic variation of bread wheat varieties using microsatellite markers. Euphytica, 135: 179-185.

Anderson, J. A., Churchill, G. A., Sutrique, J. E., Tanksley, S. D. and Sorrells, M. E. (1993). Optimizing parental selection for genetic linkage maps. Genome 36:181186.

Anonymous (2016). Agricultural Statistics at a Glance. Ministry of Agriculture \&
Farmers Welfare, Government of India. pp.236.

Botstein, D., White, R. L., Skolnick, M. and Davis, R. W. (1980). Construction of genetic linkage map in man using restriction fragment length polymorphisms. Am J Hum Genet, 32:314-331.

Chaudhary, A. S., Sachan, S. K. and Singh, R. L. (2006). Studies on varietal performance of turmeric (Curcuma longa L.). Indian Journal Crop Science, 1(1-2): 189-190.

Hikmat, U. J., Malik, A. R. and Khan, Z. S. (2011). Assessment of genetic diversity of indigenous turmeric (Curcuma longa L.) germplasm from Pakistan using RAPD markers. Journal of Medicinal Plants Research, 5(5): 823-830.

Jan, H. U., Rabbani, M. A. and Shinwari, Z. K. (2012). Estimation of genetic variability in turmeric (Curcuma longa L.) germplasm using agro-morphological traits. Pakistan Journal of Bot., 44: 231238.

McCouch, S.R., Temnykh, S., Lukashova, A. and Coburn, J. (2001). Abundance, diversity and applications of microsatellite marker in rice genetics IV. IRRI, Manila, Philippines, 117-135.

Nayak, S., Naik P. K., Acharya, L.K. and Pattnaik, A.K. (2006). Detection and evaluation of genetic variation in 17 promising cultivars of turmeric (Curcuma longa L.) using nuclear DNA content and RAPD markers. Cytologia, 71: 49-75.

Sasikumar, B. (2005). Genetic resources of Curcuma diversity, characterization and utilisation. Plant Gen. Res, 3: 230-251.

\section{How to cite this article:}

Thokchom Joydeep Singh, R.K. Patel, Savankumar N. Patel and Priya A. Patel. 2018. Molecular Diversity Analysis in Turmeric (Curcuma longa L.) Using SSR Markers. Int.J.Curr.Microbiol.App.Sci. 7(11): 552-560. doi: https://doi.org/10.20546/ijcmas.2018.711.066 